\title{
Buying on rumors: how financial news flows affect the share price of Tesla
}

\author{
Nadine Strauss \\ Institut fur Publizistik und Kommunikationswissenschaft, \\ Universitat Wien, Vienna, Austria, and \\ Christopher Holmes Smith \\ Annenberg School for Communication and Journalism, \\ University of Southern California, Los Angeles, California, USA
}

\begin{abstract}
Purpose - The purpose of this paper is to research how corporate communication regarding a specific corporate event (i.e. Tesla's tweets about a new product) as well as the framing of both the event itself and the market reactions therewith in the news media influence the formation of the share price of the respective company over time. In so doing, the study provides insights into the nature of market-moving information and the role of financial news flows in shaping market reactions in today's high-frequency news and information environment.

Design/methodology/approach - Using a multi-method case study approach, combining quantitative intraday event studies with a qualitative text analysis of financial online news and tweets by Elon Musk and Twitter, the authors shed light on the complex interaction between market events, financial information and stock market reactions. The analysis covers a period of four days, encompassing the announcement and introduction of the new battery pack for Model S and X by Tesla as well as the accompanying and follow-up reporting by the financial news media.

Findings - Findings show that market reactions are driven by business events and expectations among the market rather than the follow-up reporting by financial news media. Financial online news instead seems to heavily rely on Elon Musk's attention-triggering news to sustain its 24-h airtime with a variety of reporting tools, keeping the highly demanded audience engaged. Eventually, Twitter accounts of media visible companies and personalities, such as Tesla and its CEO Elon Musk, have been found to be useful market information sources for day traders and shareholders to trade at a profit.

Originality/value - The study is a response to recent discussions about the legitimacy of Twitter communication by CEOs or representatives of listed companies. The findings show that Twitter communication needs to be well considered in light of strict market regulations (e.g. SEC in the USA) regarding insider-trading and the publication of market-relevant information. In addition, corporate financial communication should avoid impetuous communication via social media channels as this could have deterrent effects on the market valuation of a listed company.
\end{abstract}

Keywords Financial markets, Event study, Financial reporting, Stock markets, Market reactions,

Financial news

Paper type Research paper

The flow of information can severely impact the formation of stock prices (Mitra and Mitra, 2011). Similarly, media representations of companies might not only have a considerable influence on corporate reputation (cf. Fombrun and Shanley, 1990), but might also affect the fluctuations of their share prices (e.g. Scheufele et al., 2011). Scholars have argued that

(C) Nadine Strauss and Christopher Holmes Smith. Published by Emerald Publishing Limited. This article is published under the Creative Commons Attribution (CC BY 4.0) licence. Anyone may reproduce, distribute, translate and create derivative works of this article (for both commercial and non-commercial purposes), subject to full attribution to the original publication and authors. The full terms of this licence may be seen at http://creativecommons.org/licences/by/4.0/legalcode

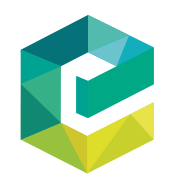

Corporate Communications: An International Journal International Journal
Vol. 24 No. 4,2019
pp. $593-607$ 
CCIJ

24,4

the way a company is presented in the news influences public evaluations and opinions about the company's future business prospects, and hence its market valuation (Pollock and Rindova, 2003). Previous research, however, has investigated the link between media representations and the stock market from a rather static perspective, measuring, for example, the amount of coverage and sentiment expressed in news items over a certain amount of time and the stock market reactions therewith (e.g. Scheufele et al., 2011; Strauß et al., 2016; Tetlock, 2007). Subsequently, studies in this research area have not paid attention to the complex dynamics of event-driven news coverage and its effects on stock market prices. It remains unclear how breaking issues can move the market gradually and how various outlets report on the issues over time, affecting investors' trading-decisions.

In addition, such event-driven news coverage increasingly originates in the realm of social media (Bollen et al., 2011). Quarterly earnings announcements, product introductions or news by the CEO of a company are regularly released on Twitter and other social media channels to inform stakeholders (Malhotra and Malhotra, 2016). Hence, when investigating business events and their effects on the stock market in today's fast-moving news and information environment, it becomes crucial to distinguish between sources of information (e.g. social media vs news agency vs press release), the dissemination of news across various media outlets, the timing of coverage, and therewith, the dynamic effects of changing reporting on corporate news and stock market prices over time. Thus, the overarching research question of this study reads:

$R Q 1$. How do financial news flows about corporate events influence the stock market prices of companies over time?

However, previous research has led to the "logical conclusion that there is no conclusive and systematic relationship between big news and big price movements" (Schuster, 2006, p. 50). Therefore, instead of looking at aggregate effects of corporate news on stock market prices (e.g. Scheufele et al., 2011; Strauß et al., 2016; Tetlock, 2007), researchers are advised to take a micro-level perspective when investigating how news flows affect stock market prices. In this vein, a case study approach has been chosen to study the highly media visible company Tesla Motors and its introduction of the new battery pack for Model S and Model X in August 2016. The findings give insights into Tesla's Twitter communication (including its CEO, Elon Musk) about the product introduction, the emerging news dynamics among the major financial news outlets in the USA therewith, as well as Tesla's stock market reactions as a response to the news and information cycle.

\section{Theoretical background}

The relationships between financial news and the stock market

Knorr Cetina and Bruegger (2002), who studied foreign-exchange dealing rooms through an economic sociological lens, argue that "market reality itself is knowledge generated, that is, has no existence independent from the informational presentation of the market on screen that is provided by news agencies, analysts, and traders themselves" (p. 915). These information flows exist within a crowded and turbulent global media ecosystem where the competition to capture attention across linear broadcast feeds, digital on-demand services and social media networks is fierce. In this "attention economy," media users - including variously situated social agents actively engaged in the screen-driven activities that constitute modern financial markets - become collectively habituated to a wide variety of discursive formats and presentation styles that continually mount communicative attempts to cultivate awareness and engagement in the hearts and minds of audiences and stakeholders (Webster, 2014). The normalized conventions of these content formats create an everyday state of what media scholar John Ellis characterizes as "mundane witnessing" (Ellis, 2009). Within this context, media studies theorists have shed light on the extraordinary circumstances - variously 
characterized as "media events" (Fiske, 1994), "mediatized rituals" (Cottle, 2006) or "media spectacles" (Kellner, 2003) - that frequently erupt within the news cycle and shatter the quotidian pattern of media reception, thereby eliciting more intense forms of coverage rife with "endless detail and speculation about further details" on the unfolding story (p. 85).

When describing financial news flows in the global, attention-seeking and ubiquitous media ecosystem, the issue-attention cycle as introduced by Downs (1972) can be used to explain how financial information develops into a public issue that becomes integrated into market prices until it reaches equilibrium again (cf. Fama, 1970). Downs introduced the framework more than 50 years ago when describing the cyclical process of how attention is paid toward domestic issues in the USA. The five stages are divided in: pre-problem state, alarmed discovery and euphoric enthusiasm, realizing the costs of significant progress, gradual decline of public interest and the post-problem state. In the theory, Downs focuses on the issue "ecology," explaining how public attention in America has slowly increased toward environmental issues, heighted and demanded political action, but eventually resulted in decreased public interest, being ultimately replaced by other seemingly more important issues at the time.

What is particularly appealing about Downs' (1972) issue-attention cycle for studying financial news flow is that it takes a public perception perspective, particularly focusing on the attention paid toward certain issues in the news media and the public. In fact, scholars in communication science have long stressed the power of the media in intervening public opinion in terms of the agenda-setting theory and framing theory (e.g. McCombs and Shaw, 1972; Iyengar and Kinder, 1987; Shoemaker and Reese, 1996). Agenda-setting presumes that the attention media pays toward certain issues gets transferred to the public agenda (McCombs and Shaw, 1972). In other words, the more the media talks about a certain topic (e.g. Tesla product introduction), the more likely the audience will recall this topic and rate it as important. Similarly, framing theory suggests that public perceptions of characters (e.g. politicians), topics or institutions are dependent on how the news media frame these (Carroll and McCombs, 2003; Golan and Wanta, 2001). As a consequence, the framing of a certain topic, institution or person in the media in a positive or negative light might impact the way the public perceives and eventually evaluates the objects of the media representations.

Hence, following agenda-setting and framing theory, financial news might also impact how the financial audience perceives the financial markets, or specific stocks in particular (cf. Pollock and Rindova, 2003). Studies in finance, business and sparsely in communication science have made use of this alleged link between media and the public when researching the relationships between news media and the stock market. The vast amount of work ranges from different news media (e.g. The Wall Street Journal: Tetlock, 2007), information outlets (e.g. Reuters news: Uhl, 2014) to the focus on different characteristics of news such as emotions (e.g. Bollen et al., 2011) or expert opinions (e.g. Bar-Haim et al., 2011). While some findings point to correlations between news, the sentiment of the coverage and the stock market on an aggregate level (but are not generalizable), it is still open for discussion how this relationship can be described at the micro-level; hence, when studying news dynamics for a specific corporate event or a specific listed company.

Indeed, scholars in news analytics have highlighted the importance of news flows and the fact that news can switch from positive to negative sentiment for a specific company over time (Moniz et al., 2011). Instead of investigating accumulated reactions to news items, Moniz and colleagues argue that a focus on short-term influences of news events on share prices is more appropriate. Similarly, it is argued in this study that the accumulated and mostly one-way media effect assumption is an oversimplification that takes neither the complexity of multi-media news distribution, nor the diversification and temporal sensitivity of company-related market sentiment into account. In this sense, investigating the emergence of financial news for a particular corporate event over time might give more insights into how the flow of news affect stock market prices in the course of financial reporting. 
CCIJ

24,4

The case: Tesla Motors. In the past years, shareholders of Tesla Motors have witnessed strong fluctuations of Tesla's share price as a result of tweets by Elon Musk, containing promising information about the company and its future plans. In August 2018, for example, Musk tweeted that he is considering taking the company private at a price of $\$ 420$ a share. The market reacted with turmoil and the trading of Tesla shares was briefly suspended on the Nasdaq stock exchange (The Economist, 2018). Musk is known for his tweets that offer hints about new products, announcements or information on Tesla that in turn spawn interest among the financial community and various media outlets to report on the corporate news and market reactions therewith (Malhotra and Malhotra, 2016). Hence, acknowledging Tesla as a newsworthy technology company, Tesla serves as the ideal case study (Yin, 2013), to research how corporate tweets regarding a specific corporate event (i.e. product introduction) affect its share price, and how the framing of both the event itself and the market reactions therewith in the news media influence the formation of the share price over time.

\section{Data and methods}

\section{Case selection}

Tesla is a US-based automobile company that focuses on the production of electric cars and batteries, with Elon Musk as the CEO of the company. In 2016, Tesla was frequently covered in the news regarding new product introductions (e.g. Model 3 in March), product innovations (e.g. more efficient batteries for its models in August), accidents caused by its self-driving car in May 2016, or the acquisition of SolarCity in August 2016. For this case study, the introduction of the new electric-car battery for the Model S and Model X in August 2016 was selected. The news about the new battery did not only cause broad news coverage across various financial news media outlets, but also let the share price of Tesla respond considerably over the period of reporting. Although this corporate event might appear less relevant when compared to the introduction of Model 3 or the accidents with the self-driving Tesla cars, the choice to investigate the introduction of the new battery was driven by two reasons: it offered a manageable set of data that was adequate for a qualitative, manual text analysis and it was appropriate to conduct intraday event studies because there was no other news at the center of media coverage related to Tesla than the introduction of the new battery on the day of the announcement.

\section{News data}

To get insights into the news dynamics across various financial online news outlets and the share price of Tesla, seven top news sources for traders on the US market, including Bloomberg, CNBC, CNN Money, Forbes, Financial Times, Reuters and The Wall Street Journa [1] were assessed. For the analysis, all online news articles that were published by these outlets were collected, including videos, slide shows and audio files from the day of the announcement (August 23, 2016) until three days after (August 26, 2016). In total, 43 news items were analyzed (see for an overview Figure 1).

\section{Tweets}

Besides considering the online news articles, the role of Tesla and its CEO, Elon Musk, who announced the new battery on Twitter were also objects of the analysis. Most relevant in this sense was the tweet by Elon Musk in which he promoted the presentation of a new product in the morning of the August 23 as well as one update on this notification during the day, the tweet by the official Tesla account about the actual product introduction, and the eventual retweet by Musk of the product presentation in the afternoon. 
In order to compare how the stock market price of Tesla reacted to the announcement of the new product by Elon Musk on Twitter and the online news reporting thereafter, intraday stock market quotes, including the share price and trading volume for Tesla (TSLA) for the period of analysis (August 23, 2016-August 26, 2016) were downloaded from a Bloomberg terminal. Daily stock market data were retrieved from Yahoo finance.

\section{Event studies}

To find out whether the tweet by Elon Musk or the actual presentation of the new product by Tesla had a significant effect on the returns of Tesla's share price in the short run, event studies were conducted. Event studies are common practice in research fields such as finance, management and economics. In essence, an event study measures the impact of a particular event on the market value of a company (MacKinlay, 1997). However, while common event studies make use of daily stock quotes, this study uses minutely stock market quotes of one trading day (i.e. the day of the announcement of the new battery by Tesla: August 23, 2016). It is argued that the investigation of intraday stock quotes gives more insights into the immediate reactions of the Tesla share price to the announcement of the new battery than daily quotes. In fact, because Tesla had been associated with various negative issues in Summer 2016 (e.g. Autopilot crashes, SolarCity acquisition), the actual impact of the battery announcement on the Tesla share price would have likely become wiped out when considering daily instead of intraday stock quotes.

Procedure. When looking at the fluctuations of the share prices of Tesla during the day of the announcement of the new battery (August 23, 2016; see Figure 2), there is one point in time in which the price seems to have reacted strongly positively and one in which the share price of Tesla slumped considerably. The rise can be spotted around $11.30 \mathrm{a} . \mathrm{m}$. EST; hence, about the time when Elon Musk made the announcement about a new product on Twitter. The dip can be traced around 15.30 p.m. EST, very likely when Tesla eventually presented the new battery to the public. In order to find out which of the two identified swings of the Tesla share price had a significant impact on its returns, two event studies were run. To do so, the procedure according to MacKinlay (1997) was followed.

In the first step, the events during the day of the announcement (August 23, 2016) were identified. The first event happened at 11.23 a.m. EST when Elon Musk tweeted that there would be a product announcement by Tesla at noon, California time. The second event was identified as the actual product announcement by Tesla at 3.30 p.m. EST. In the second step, event windows were defined, which are the periods in which the security prices of the company are inspected for changes as a reaction to the event. For this study, an event

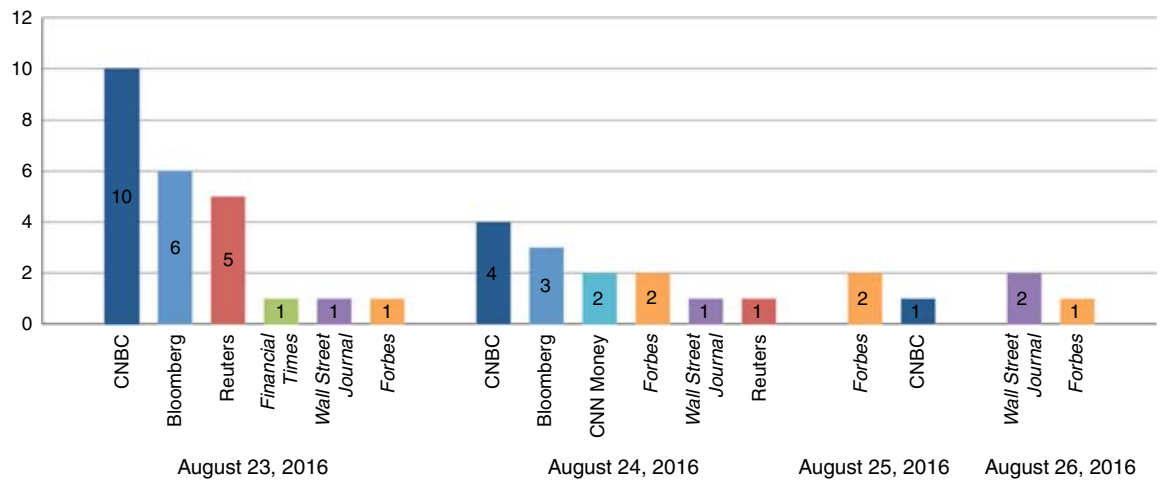

Figure 1 . Distribution of financial news on the new Tesla battery from the day of the announcement (August 23, 2016) until three days after (August 26, 2016) 
CCIJ

24,4

\section{8}

Figure 2.

Intraday Tesla share prices on

August 23, 2016

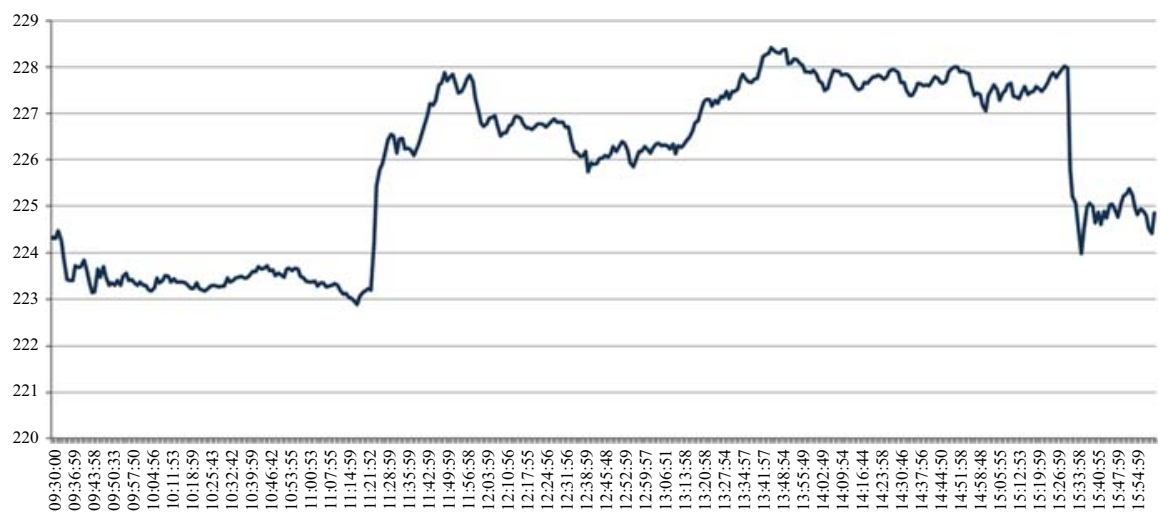

window of $10 \mathrm{~min}$ was chosen to investigate how Tesla shares reacted up to $10 \mathrm{~min}$ before and after the respective events took place. To estimate the impact of the events on the Tesla shares, the abnormal returns were calculated. The abnormal return is defined as:

$$
A R_{i t}=R_{i t}-E\left(R_{i t} \mid X_{t}\right),
$$

where $A R_{i t}$ is the abnormal return for stock $i$ (Tesla) at time point $t$ (trading minute on August 23, 2016); $R_{i t}$ the actual return; and $E\left(R_{\mathrm{it}} \mid X_{t}\right)$ the expected return[2] conditional on the return of a comparable market portfolio $X$ at time point $t$ (MacKinlay, 1997). Given that for this study the market model was chosen (MacKinlay, 1997), $X$ is the market return of the Nasdaq index - the index on which Tesla is listed.

In the following step, the estimation window was selected, which is commonly a meaningful number of trading time points prior to the event. For the first event $102 \mathrm{~min}$ were used, as this was the maximum number of minutely stock quotes that was available prior to the tweet by Elon Musk released at 11.23 a.m. EST on that day. For the second event (i.e. the actual announcement at 15.30 p.m. EST), 252 trading minutes were used. 252 time points is also the common estimation window employed in event studies (cf. MacKinlay, 1997). By means of the parameter estimates of the normal performance model (intercept, slope), the abnormal returns could be calculated. Afterwards, the accumulated abnormal returns were estimated to get more insights in the impact of the particular event on the share price of Tesla [3]. Eventually, it was tested whether the abnormal returns of Tesla were significantly different from the expected returns $10 \mathrm{~min}$ prior and $10 \mathrm{~min}$ after the events occurred by conducting two-tailed $t$-tests. The results for the two event studies are presented together with the results of the qualitative text analysis in the results section.

\section{Text analysis}

The two authors of this study read and coded the news items of the seven top financial online news outlets by means of a semi-structured codebook. Rather than using variables with pre-specified values, the codebook was constructed with open questions for each variable, giving the coders the opportunity to assess each news item with an open approach. Besides manifest variables, such as name of the coder, news outlet, date, time, title, author, added content (e.g. video, slide shows, audio), the codebook also included open categories such as pro and contra arguments raised about Tesla and the new battery, voices raised in the news item (e.g. direct quotations by Elon Musk, financial analysts or reporters), information and prospects about Tesla's share price, the main conclusion of the news item, the prevalent sentiment of the news items and other remarks. The two coders discussed the 
categories of the codebook together and solved disagreements before the actual coding started. The sample of news items was divided into two sets so that every coder was able to provide in-depth notations for the respective news items. After sorting all news items based on the date and time of release, a clear timeline of the news reporting emerged that facilitated the investigation of the news dynamics across outlets over time.

\section{Results}

Is it all just buying on rumors?

On August 23, 2016 at 11.23 a.m. EST, Elon Musk, the CEO of Tesla, announced on Twitter that there would be a "product announcement at noon California time today." Not only did this tweet generate considerable engagement on Twitter (i.e. 5,251 retweets; 14,330 likes), it also caused the Tesla share price to jump 1.4 percent from $\$ 223.14$ at 11.23 a.m. to 226.37 at 11.30 a.m., with a trading volume of 549,981 shares in that period, which accounted for more than an eighth of the total trading volume on that day for Tesla (4,784,400 shares). Although it was not clear what the actual product announcement of Tesla would be at that moment, it seemed that investors bid up Tesla's share price on pure speculation. While investors reacted with the acquisition of Tesla shares immediately, the mainstream financial news outlets started to speculate about possible interpretations of the cryptic announcement by Elon Musk. Reuters was among the first that reported with a short statement at 11.40 a.m. EST on the tweet and the rising share price of Tesla therewith: "rose more than 1 percent after the post and were recently trading up \$3.69."

The results of the event study in which this first tweet by Elon Musk was treated as an event showed that there was indeed a significant market reaction of the abnormal returns of Tesla at the moment when the tweet was released (11.23 a.m. EST). Besides a few minutes, the significant impact of the event on the Tesla share price persisted up to $9 \mathrm{~min}$ after the tweet was released (see Table I and Figure 3). No significant abnormal returns could be found for the $10 \mathrm{~min}$ before the tweet was published. However, the tweet did not have a lasting effect on the Tesla share price. Already $30 \mathrm{~min}$ after the tweet was published, Tesla stocks declined 0.4 percent down to $\$ 223.37$, slightly higher than before the announcement.

Not long after the first reporting on Elon Musk's tweet by Reuters, CNBC weighed in at noon EST and published a video with a short online news article, commenting on the tweet and speculating what the announcement could be about. Phil LeBeau, the Anchor of "Halftime Report" at CNBC reminded the network's viewers that Musk's tweets are not typically harbingers of "big news." Furthermore, when describing the intraday market reactions of Tesla shares prior to Musk's tweet in CNBC's news segment, Jon Najarian, the Najarian Family Office Co-founder, saw some unusual activity. He contemplated that there might have been some investors who had access to inside information. When looking

\begin{tabular}{|c|c|c|c|}
\hline \multicolumn{2}{|c|}{ Event 1: Tweet by Elon Musk (11.23 a.m.) } & \multicolumn{2}{|c|}{ Event 2: Announcement by Tesla (3.30 p.m.) } \\
\hline Time & Abnormal returns & Time & Abnormal returns \\
\hline 11.23 a.m. & $8,553^{* * * *}$ & 3.30 p.m. & $-13,263^{* * *}$ \\
\hline 11.24 a.m. & $9,860 * * *$ & 3.31 p.m. & $-3,982^{* * * *}$ \\
\hline 11.25 a.m. & $3,322 *$ & 3.33 p.m. & $-3,293^{* * *}$ \\
\hline 11.27 a.m. & $2,133^{*}$ & 3.34 p.m. & $-3,877 * * *$ \\
\hline 11.28 a.m. & $1,984^{*}$ & 3.35 p.m. & $3,314^{* *}$ \\
\hline 11.31 a.m. & $-2,930 * *$ & 3.36 p.m. & $3,022^{* *}$ \\
\hline 11.32 a.m. & $2,301^{*}$ & 3.39 p.m. & $-2,013^{*}$ \\
\hline
\end{tabular}

Notes: Reported are significant abnormal returns of Tesla for Event 1 (the moment when the tweet by Elon Musk was released) and Event 2 (the moment when Tesla made the official announcement of the new battery); two-tailed $t$-tests; Event 1: $\mathrm{df}=100$; Event $2: \mathrm{df}=251 . * p<0.05$; $* * p<0.01 ; * * * p<0.001$

Buying on rumors 
CCIJ 24,4

\section{0}

Figure 3.

Intraday event study for Tesla shares at the moment when the tweet about the new product announcement was released by Elon Musk on August 23, 2016 at 11.23 a.m. EST

Figure 4 .

Intraday share prices of Tesla between 11.00 a.m. and 11.30 a.m. on August 23, 2016 at the intraday stock quotes of Tesla right before the release of the tweet by Elon Musk (see Figure 4), it indeed seems that there might have been some preliminary trading on Tesla shares before Musk tweeted about the upcoming product introduction. Later that day, Elon Musk sent another tweet at 3:02 pm, advertising the revelation, "Journalists Q\&A for 30 mins and embargo ends at 12.30 ." However, Tesla shares reacted this time only mildly (0.6 percent), rising from $\$ 226.16$ at the minute of the release to $\$ 227.48$, half an hour later.

Before the actual product announcement by Tesla at noon California time, there were two more news items published. Bloomberg reported shortly on the reactions of the Tesla share price to the tweet by Musk ("Tesla jumped 2 percent to $\$ 227.45$ at 11:53 am after rising as much as $2.3 \%$, the biggest intraday gain in two weeks") and referred negatively to the investigation with regard to the Autopilot car crash as well as to the "trimmed" full-year forecast. In the meantime, $\mathrm{CNBC}$ released another online news article with a video of its show "Closing Bell" in which Aswath Damodaran, Chair of Finance Education at the NYU Stern School of Business, analyzed "cash burn" companies; hence companies that require high investments before they become profitable. Although Elon Musk's announcement was not mentioned directly in the segment, Damodoran reflected upon Tesla as a cash burn company, criticizing the acquisition of SolarCity as the "malignant cash burn part" and
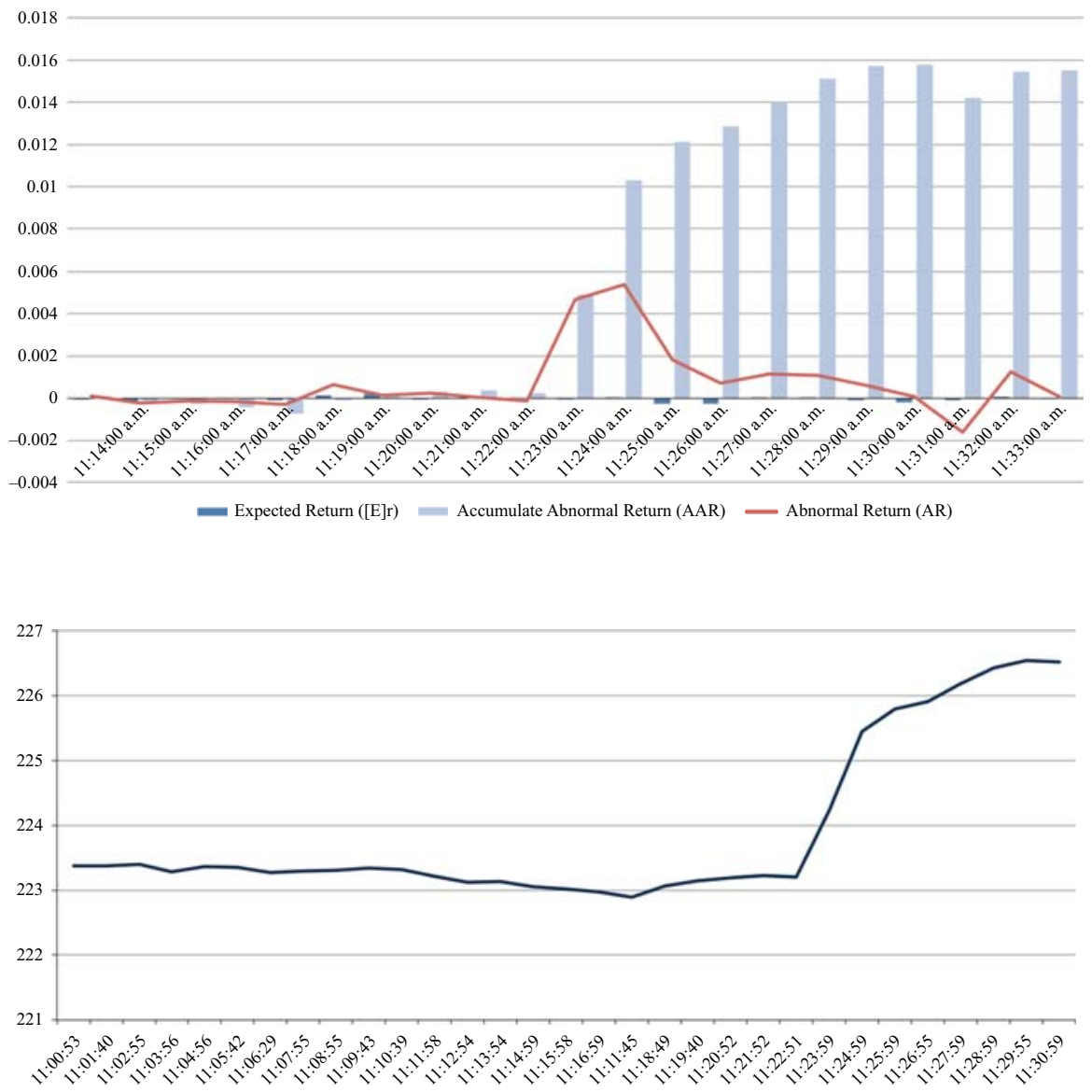
automobile business as the "benign cash burn part." Just 1 min before the actual announcement of the new product, Tesla's stock was up at $\$ 228.09,1.7$ percent higher than its opening price that day.

\section{The big news - or rather the moment of the big disappointment?}

Reuters and Bloomberg were the first to report on the revelation of the new product by Tesla at 3.30 p.m. EST. Right after Elon Musk himself retweeted a tweet by the official Tesla Twitter account, saying "Introducing P100D with Ludicrous Mode, more performance \& range for Model S \& Model X" at 3:36 p.m. The tweet was linked to a press release on Tesla's website, where the specifics of the new electric battery were described in more detail. As the front-runner of the news, Reuters wrote in a short article that Tesla is going to provide a "100 kilowatt hour (kWH) battery for its Model S and Model X cars." Simultaneously, Bloomberg published a video segment in which David Welch reported on the specifications of the battery upgrade and news regarding the Autopilot issue. While Welch stated that the technological advancement of the battery was only "marginal" or "incremental," he saw the fact that Tesla could say that it had the "fastest car in the world" as "significant marketing news" for Elon Musk.

Only 2 min later, $\mathrm{CNBC}$ picked up on the Tesla news. In an online article with a short video segment of CNBC's "Breaking News," Phil LeBeau reported on the specifications of the new battery. Interestingly, the Tesla upgrading strategy with its new battery was positively compared with the Apple business strategy ("now you start looking at it like an Apple store") in another video by CNBC of the show "News Alert" (5.19 p.m.). Although the overall tone of CNBC's "Breaking News" was positive, there was also some criticism. Reporters pounced upon the fact that Musk did not respond to any question during the conference call relating to the production problems with the Model 3 vehicles or the autopilot accident issue. In this regard, the anchors of CNBC's "News Alert" show added that the shares of Tesla were "coming back to earth," speculating if this points to an "overriding concern" of Tesla investors about the added value of the new battery features for Tesla.

When looking at the stock market reactions of the Tesla shares just after the announcement and the first reporting on the news, it seemed that the market rather responded with disappointment to the news about the improved battery pack by Tesla. With a trading volume of 223,773 shares within 2 min, the stock market price went from $\$ 228.09$ at 3:29 p.m. to $\$ 224.75$ at 3:31 p.m., losing 1.5 percent of its share price. The results of the event study support these observations (see Table I and Figure 5). Treating the announcement by Tesla at 3.30 p.m. as an event, significant negative market reactions of the Tesla shares up to $9 \mathrm{~min}$ after the release appeared (except for minute 3.32 p.m., 3.37 p.m. and 3.38 p.m.). Hence, in comparison to the reactions to the tweet by Elon Musk in the morning, the market responded exactly in the opposite direction. It seemed that shareholders were expecting something more from Tesla than only an improved battery pack.

Before the Nasdaq stock market closed that day with a Tesla share price of $\$ 224.84$, there was only one more news item by Reuters published online in which the specifics of the new battery were shortly outlined. However, despite the closing of the financial markets on the east coast, the financial news did not stop reporting on the new announcement by Tesla. $\mathrm{CNBC}$ continued its reflection on the specifics of the new battery in the "Closing Bell" show. Just 2 min later, a new video was released by CNBC, in which a Senior Research Analyst at Oppenheimer, Colin Rusch, gave his assessment of the new product announcement by Tesla on the phone, supporting his position on the stock despite identifying the new battery package as only an "incremental product improvement" and raising concerns about the acquisition of SolarCity by Tesla. CNBC, on the other hand, released a news item with a video of the show "Behind the Wheels" later that day in which Karl Brauer, Senior Analyst at the automobile research and evaluation company Kelley Blue Book, pointed out that 
CCIJ

24,4

\section{2}

Figure 5.

Intraday event study for Tesla shares at the moment when the

Tesla made the actual product

announcement on

August 23, 2016 at

3.30 p.m. EST
0.005

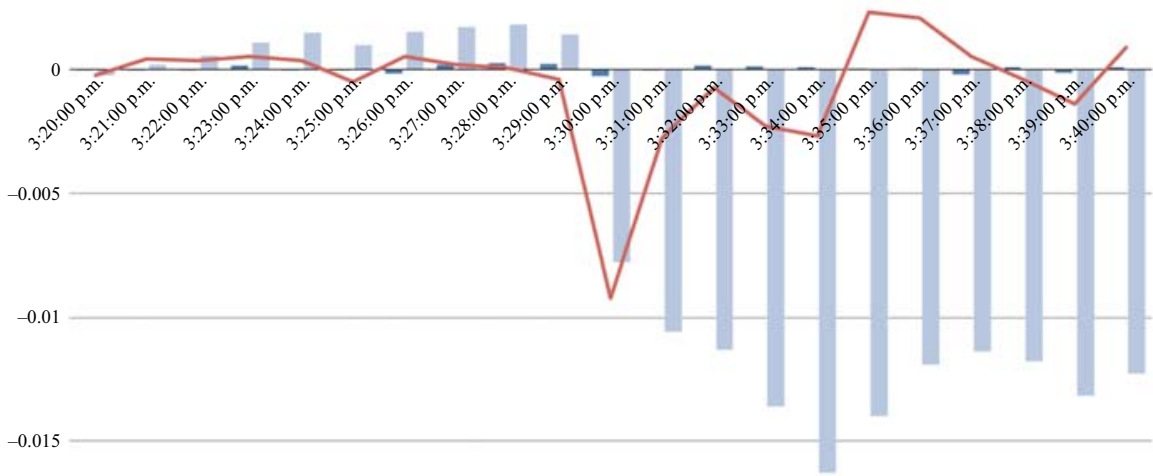

$-0.02$

Expected Return [E]r $=$ Accumulate Abnormal Return (AAR) $\quad$ Abnormal Return (AR)

Tesla needed more than an "incremental improvement." He considered the high price as the main problem with the new upgrade of the battery.

In the course of the evening, a few more online articles were published. CNBC, The Wall Street Journal and the Financial Times neutrally reported on the news and the stock market reactions therewith. In contrast, Bloomberg and Forbes critically reported on the introduction of the new battery. Bloomberg criticized that Tesla "ha[d] already pushed investors' horizons out so far" given the numerous announcements Elon Mask had made that year. Forbes saw the new battery as "an answer to a question few were asking." In particular, Forbes listed a number of challenges Tesla was still facing, such as the mass production of Model 3 or the outcome of the investigations with regard to the Autopilot accidents. Not only did Reuters emphasize these challenges in another online article as well, the problem with the SolarCity acquisition and the accidents with Tesla's Autopilot cars were also taken up in CNBC's show "News Alert" released later that day. As one expert in the show stated, "the SolarCity deal to me is partially out of necessity to keep the whole magic kingdom alive."

\section{The next day: follow-up reporting}

The next day news items were released that provided a morning briefing for investors before the markets on the New York Stock Exchange opened. CNN Money, for example, warned that Tesla could experience "higher-than-normal volumes Wednesday after it unveiled a new battery," while Reuters, CNBC and The Wall Street Journal only briefly and neutrally referred to the introduction of the new battery by Tesla from the previous day. In the hours before the stock market opened, both $\mathrm{CNBC}$ and Bloomberg released video segments that were already published the day before, accompanied with online news articles. Furthermore, Forbes published an online article offering its rationale for placing Tesla at the top of the "Forbes Most Innovative Companies" list in 2016. Also giving room for expert opinions, the analysis by Forbes was more extensive when compared to previously published news articles by other outlets. Various arguments were given why Forbes had decided to designate Tesla as the most innovative company (e.g. Autopilot, mobile app for shared Tesla cars, Gigafactory).

It seemed that the positive follow-up reporting on Tesla and its new battery as well as the rather positive evaluations of analysts had pushed Tesla share prices up that morning. 
With $\$ 227.05$, investors bid up Tesla shares by almost 1 percent compared to its closing price $\$ 224.84$ from the previous day. This increase, however, remained unnoticed by the financial news. Instead, Bloomberg released a piece of the column "Money Stuff" by Matt Levine in which he commented on market news from the previous day, shortly mentioning the introduction of the new battery by Tesla, but not its increased opening price.

Compared to the previous day, the online news articles by the financial news outlets appeared much longer, providing more insights and background information. Forbes, for example, released another piece in which Robert Bradley Jr, the Founder and CEO of the Institute for Energy Research, critically commented on Tesla and the fact that the company is mainly based on governmental funding. Before the market closed that day with Tesla shares dropping almost 2 percent from its opening price down to $\$ 222.62$, reaching practically the share price of the day previous to the battery announcement, two more financial news items were identified. CNN Money neutrally reported in an online article on the new battery for Model $\mathrm{S}$ and $\mathrm{X}$ with a short clip that showed the Tesla Gigafactory; Bloomberg released another item which included an audio file in which two reporters spoke about Tesla's new battery.

\section{When news is no longer news}

In the following days of the week, the amount of reporting on the new battery by Tesla waned. The major financial news sources such as Reuters or Bloomberg were not even writing about it anymore. Instead, there were two more articles by Forbes on August 25, 2016 that were only indirectly related to the Tesla announcement from two days ago, but which put Tesla and its stock in a negative light. One in which Professor, Pop-Science Author and Blogger Chad Orzel criticized carmakers' methods of acceleration tests, including Tesla. And another article by Forbes in which Tesla was identified as one of the most shorted Nasdaq 100 component. The same day, CNBC released a news item in which the benefits and specifics of the new battery pack were outlined one more time.

Overall, the follow-up reporting by the financial news outlets focused less and less on the new battery by Tesla. On Friday, August 26, 2016, The Wall Street Journal published an article about the advanced driver-assistance programs in which the news about the new battery pack was only mentioned in passing. In another article that was published $15 \mathrm{~min}$ after, The Wall Street Journal argued that electronic cars are at the forefront while positioning Tesla as the "standard-bearer." Similarly, an article published by Forbes placed Tesla with its Model 3 as the model example for electronic carmakers. However, the plea for electronic cars and the laudatory words for Tesla in these articles had little impact on the stock price of Tesla that day. Although the stock market price of Tesla slightly recovered on August 25, 2016 with an opening price of $\$ 223.11$, up 2 percent from its closing price the previous day, it closed $\$ 2.15$ lower at $\$ 220.96$. Tesla ended the trading week with a price of $\$ 219.99,1.9$ percent lower than its opening price $(\$ 224.17)$ on Monday morning.

\section{Discussion}

\section{Financial issue-attention cycle: reporting on news or making news?}

Recapitulating the news reporting about the announcement of the new battery by Tesla, the analysis has given valuable insights into the financial news reporting cycle and the emergence of business news and its impacts on Tesla's stock market price, respectively. Partly in accordance with the first stage of the issue-attention cycle (Downs, 1972), the announcement of the new battery has raised limited attention in the media, given that only few news outlets (Reuters, CNBC, Bloomberg) reported on the tweet by Elon Musk right after. However, the public, and particularly investors, responded considerable, given that Tesla's share price rose mostly after the tweet by Elon Musk that conveyed the ambiguous announcement of a new product introduction in the morning. 
CCIJ

24,4

604

In the second stage, according to Downs, attention gets sparked and more people become aware of the issue and are optimistic that the issue can be solved. In case of Tesla, the vast amount of reporting on the new battery could indeed be found on the day of the announcement itself. Even though Tesla had not yet specified the news, it seemed that the news outlets were making use of every bit of information to fill their airtime and to report on the speculations before Tesla made the actual product introduction. It occurred that both the media and the public were eager to hear more about the opaque announcement by Elon Musk. While the news media needed the information to make sense of the news, investors sought the information to find out how to best trade on the new announcement.

The third stage in the issue-attention cycle is reached according to Downs (1972) when the public recognizes the connection between the solutions and the problem, realizing what it would eventually cost to solve the issue. Although there was not an explicit need in "solving" the new product announcement by Tesla, the third stage as defined by Downs can be spotted in this case when the media and investors noticed that the new battery did not meet the expectations of the market; hence right after the release of the new product by Tesla. On the one hand, the media reported extensively about the implications of the new battery for Tesla and its share price, determining that it was overall only an "incremental improvement"; investors, on the other hand, reacted with disappointment in the new product by selling their shares right after the announcement.

At the height of the discussion, the financial media kept on reporting on the Tesla news, even after the market had closed. CNBC, Bloomberg and Reuters presented themselves as frontrunners, providing ongoing reporting to its audience with updates on the new product introduction, featured with videos, audios and photo slide shows. In so doing, the TV news shows by $\mathrm{CNBC}$ and Bloomberg made use of various financial reporting tools, such as discussion tables, staffed with experts from the automobile and tech industries, live call-ins (e.g. with analysts, conference calls), interviews with experts and intraday stock market charts, enabling reporters to discuss the immediate stock market reactions in real time (cf. Ahern and Sosyuro, 2015). While these TV shows and the online news articles published by CNBC, Reuters and Bloomberg were rather neutral in their reporting about the specifics of the new battery, relying heavily on citations by Elon Musk and Tesla, Forbes and The Wall Street Journal appeared to provide more in-depth and partial reporting. The criticism against Tesla overall seemed to resonate. In particular, the SolarCity deal the Autopilot crashes as well as Tesla's struggle to produce and deliver an affordable vehicle for the mass were seen as the main reasons why investors did not react with enthusiasm to the news about the battery.

Eventually, the fourth stage of the issue-attention cycle is characterized by a decreasing interest for the issue on the side of the public as argued by Downs (1972), followed by the fifth post-problem stage, which emerges when the issue has been replaced by another, new issue or topic. These final two stages become reflected in the media coverage about Tesla's new battery during the three days after the announcement when reporting about the new product overall declined and attention in the financial news seemed to have switched to other, seemingly more relevant, topics. Forbes and the Wall Street Journal, for example, presented more detailed analyses of Tesla in the days after the announcement, yet focusing on other topics such as Tesla's business strategy or issues the company was facing (e.g. Tesla nominated as the most innovative company; most short-selling share). However, Tesla's share price did respond to the follow-up news reporting in the subsequent days. In essence, there was little left behind from the initial enthusiasm and "rumor trading" as seen right after the release of Elon Musk's opaque tweet on Tuesday morning.

\section{Buying on rumors and day trading}

The analysis of the news dynamics surrounding the introduction of the new battery by Tesla has shown that financial news reporting rather plays a limited role in influencing 
short-term market reactions. Instead, announcements by corporations themselves (e.g. via Twitter) can trigger market participants to react immediately and - likely also for this reason - evoking a stream of further news reporting. As the event studies, but also the inspection of the stock market reactions over the course of four days have shown, the market reacted strongest to the Tesla news when Elon Musk tweeted about the new product announcement and when the news eventually got released by Tesla and retweeted by Musk. These responses imply that investors were buying on the simple speculations of what the new product announcement could have been about.

Hence, the Tesla share price reactions based on Elon Musk's tweet do not only suggest that market participants react to news items that are not yet verified, or which are still based on speculations (Hirshleifer et al., 1994; Oberlechner and Hocking, 2004), it also shows that this investor behavior is at add odds with the rational market behavior that representatives of the efficient market hypothesis promulgate (e.g. Fama, 1970). Rather than waiting until the actual revelation of the announcement and assessing the value of the news before making a trading decision, some shareholders seemed to have traded purely on the belief that other traders might also react upon this tweet and that Tesla might reveal a new product that would increase the market value of the company. In this vein, this market behavior rather seems to be in line with herd-like reactions and irrational market decisions that are caused by emotions, such as the fear of missing out on a lucrative investment (Nofsinger, 2005; Prechter, 2001; Shiller, 2003).

Following this, the subsequent slump of the Tesla stock price as soon as the introduction of the new battery was actually made resonates with Hirshleifer et al.'s (1994) findings on aggressive day trading. It appeared that some traders were actively buying Tesla shares in the morning before and after Elon Musk vaguely notified the public about a new product announcement, and then sold their shares again after the actual news was eventually revealed. By betting on the increase of the Tesla share price based on Musk's tweet about the announcement and its subsequent fall, informed day traders were able to sell their shares at the right moment, and at a profit. Hence, believing that the majority of traders will react to ambiguous information in a certain way might confer investors the opportunity to successfully trade on speculations or rumors.

\section{Implications, limitations and future research}

Based on this case study it can be assumed that being vigilant to high-profile Twitter personalities of listed corporations (e.g. the Tesla's CEO Elon Musk) might render first-hand information on investments for retail and professional investors. However, while this might provide profitable trading opportunities for day traders, it also poses a risk to companies and its share price. Besides legal issues in terms of information disclosure violations (SEC, 2013), Twitter activity by corporations and CEOs of listed companies might also lead to more speculative short-term trading of stocks which can be detrimental for a fair valuation of companies. Indeed, after Musk's tweet about considering taking the company private in August 2018, there were heated discussions whether the tweet violated the Regulation Fair Disclosure act (Ross Sorkin, 2018).

In this regard, it has to be noted that the results of this study do not allow for generalizations across listed companies. Tesla Motors with its media-savvy CEO Elon Musk can be considered an exception rather than the rule (Malhotra and Malhotra, 2016). Only few CEOs of publicly traded companies are regularly active on Twitter and use the potentials of such social media channels (42 of the 500 Fortune CEOs had a Twitter account as of September 2014; Malhotra and Malhotra, 2016). Future research is therefore invited to compare these findings to other listed companies and to organizations that do not enjoy such a strong visibility on social media. Furthermore, there might also be differences across various stock market environments, countries, industries or points in economic times. In this vein, this study has made a first step to 
invite scholars in communication science and economics alike to take a case study approach and combining qualitative and quantitative methods to explore the complex interaction between corporate events, news flows and stock market reactions.

\section{Notes}

1. Except for The Wall Street Journal, the top news sources ranking for investor were retrieved from: www.earnforex.com/articles/top-7-news-sources-for-financial-trader/; There was no article available from The Economist related to the new battery by Tesla within the period of analysis.

2. The expected return is composed of $E_{i t}=\alpha_{i}+\beta_{i} R_{m t}+\varepsilon_{i t}$, where $i$ is the Tesla share price; $\alpha$ the intercept; $\beta$ the slope; $R_{m}$ the actual return of the Nasdaq index at point $t$ (trading minute on August 23, 2016), and $\varepsilon$ is the error term.

3. The accumulated abnormal returns, together with the Excel calculations for each event, can be requested from the author of this dissertation.

\section{References}

Ahern, K.R. and Sosyuro, D. (2015), "Rumor has it: sensationalism in financial media", Review of Financial Studies, Vol. 28 No. 7, pp. 2050-2093.

Bar-Haim, R., Dinur, E., Feldman, R., Fresko, M. and Goldstein, G. (2011), "Identifying and following expert investors in stock microblogs", EMNLP'11 Proceedings of the Conference on Empirical Methods in Natural Language Processing, Association for Computational Linguistics, Stroudsburg, PA, pp. 1310-1319.

Bollen, J., Mao, H. and Zeng, X. (2011), "Twitter mood predicts the stock market", Journal of Computational Science, Vol. 2 No. 1, pp. 1-8.

Carroll, C.E. and McCombs, M. (2003), "Agenda-setting effects of business news on the public's images and opinions about major corporations”, Corporate Reputation Review, Vol. 6, pp. 36-46, doi: $10.1057 /$ palgrave.crr.1540188.

Cottle, S. (2006), "Mediatized rituals", Media, Culture \& Society, Vol. 28 No. 3, pp. 411-432.

Downs, A. (1972), "Up and down with ecology: the issue-attention cycle”, The Public Interest, Vol. 28 No. 1, pp. 38-51, available at: www.unc.edu/ fbaum/teaching/articles/Downs_Public_Interest_1972.pdf

Ellis, J. (2009), "Mundane witness", in Frosh, P. and Pinchevski, A. (Eds), Media Witnessing: Testimony in the Age of Mass Communication, Palgrave Macmillan, London and New York, NY, pp. 73-88.

Fama, E.F. (1970), "Efficient capital markets: a review of theory and empirical work", The Journal of Finance, Vol. 25 No. 2, pp. 383-417.

Fiske, J. (1994), Media Matters, Everyday Culture and Political Change, Minnesota University Press, Minneapolis, MN.

Fombrun, C. and Shanley, M. (1990), "What's in a name? Reputation building and corporate strategy", Academy of Management Journal, Vol. 33 No. 2, pp. 233-258.

Golan, G. and Wanta, W. (2001), "Second-level agenda setting in the New Hampshire primary: a comparison of coverage in three newspapers and public perceptions of candidates", Journalism and Mass Communication Quarterly, Vol. 78 No. 2, pp. 247-259.

Hirshleifer, D., Subrahmanyam, A. and Titman, S. (1994), "Security analysis and trading patterns when some investors receive information before others", The Journal of Finance, Vol. 49 No. 5, pp. 1665-1698.

Iyengar, S. and Kinder, D.R. (1987), News that Matters: Television and American Opinion, University of Chicago Press, Chicago, IL.

Kellner, D. (2003), Media Spectacle, Routledge, London and New York, NY.

Knorr Cetina, K. and Bruegger, U. (2002), "Global microstructures: the virtual societies of financial markets", American Journal of Sociology, Vol. 107 No. 4, pp. 905-950.

McCombs, M.E. and Shaw, D.L. (1972), "The agenda-setting function of mass media", Public Opinion Quarterly, Vol. 36 No. 2, pp. 176-187. 
MacKinlay, A.C. (1997), "Event studies in economic finance”, Journal of Economic Literature, Vol. 35 No. 1, pp. 13-39.

Malhotra, C.K. and Malhotra, A. (2016), "How CEOs can leverage Twitter", MIT Sloan Management Review, Vol. 57 No. 2, pp. 73-79, available at: http://ilp.mit.edu/media/news_articles/smr/2016 157203.pdf (accessed October 8, 2017).

Mitra, G. and Mitra, L. (2011), The Handbook of News Analytics in Finance, John Wiley \& Sons, West Sussex.

Moniz, A., Brar, G., Davies, C. and Strudwick, A. (2011), "The impact of news flow on asset returns: an empirical study", in Mitra, G. and Mitra, L. (Eds), The Handbook of News Analytics in Finance, John Wiley \& Sons, West Sussex, pp. 211-228.

Nofsinger, J.R. (2005), "Social mood and financial economics", Journal of Behavioral Finance, Vol. 6 No. 3, pp. 144-160.

Oberlechner, T. and Hocking, S. (2004), "Information sources, news, and rumors in financial markets: insights into the foreign exchange market”, Journal of Economic Psychology, Vol. 25 No. 3, pp. 407-424.

Pollock, T.G. and Rindova, V.P. (2003), "Media legitimation effects in the market for initial public offerings", The Academy of Management Journal, Vol. 46 No. 5, pp. 631-642.

Prechter, R.R. (2001), "Unconscious herding behavior as the psychological basis of financial market trends and patterns", Journal of Psychology and Financial Market, Vol. 2 No. 3, pp. 120-125.

Ross Sorkin, A. (2018), "Elon Musk's Tweets on Tesla started a tizzy. Someone should hit the brakes", News York Times, August 13, available at: www.nytimes.com/2018/08/13/business/dealbook/ elon-musk-tesla-twitter.html (accessed August 20, 2018).

Scheufele, B., Haas, A. and Brosius, H.-B. (2011), "Mirror or molder? A study of media coverage, stock prices, and trading volumes in Germany", Journal of Communication, Vol. 61 No. 1, pp. 48-70.

Schuster, T. (2006), The Markets and the Media: Business News and Stock Market Movements, Lexington Books, Oxford.

SEC (2013), "SEC says social media OK for company announcements if investors are alerted", available at: www.sec.gov/News/PressRelease/Detail/PressRelease/1365171513574 (accessed October 8, 2017).

Shiller, R. (2003), "From efficient markets theory to behavioral finance", The Journal of Economic Perspectives, Vol. 17 No. 1, pp. 83-104.

Shoemaker, P.J. and Reese, S.D. (1996), Mediating the Message. Theories of Influences on Mass Media Content, 2nd ed., Longman Publishers, White Plains, NY.

Strauß, N., Vliegenthart, R. and Verhoeven, P. (2016), "Lagging behind? Emotions in newspaper articles and stock market prices in the Netherlands", Public Relations Review, Vol. 42 No. 4, pp. 548-555, doi: 10.1016/j.pubrev.2016.03.010.

Tetlock, P.C. (2007), "Giving content to investor sentiment: the role of media in the stock market", The Journal of Finance, Vol. 62 No. 3, pp. 1139-1169.

The Economist (2018), "Elon Musk's latest madcap scheme: taking Tesla private", The Economist, August 9, available at: www.economist.com/business/2018/08/11/elon-musks-latest-madcapscheme-taking-tesla-private (accessed March 29, 2019).

Uhl, M.W. (2014), "Reuters sentiment and stock returns", Journal of Behavioral Finance, Vol. 14 No. 4, pp. 287-298.

Webster, J.G. (2014), The Marketplace of Attention: How Audiences Take Shape in a Digital Age, MIT Press, Cambridge, MA.

Yin, R.K. (2013), Case Study Research: Design and Methods, Sage Publications, Thousand Oaks, CA.

\section{Corresponding author}

Nadine Strauss can be contacted at: nadine.strauss@univie.ac.at

For instructions on how to order reprints of this article, please visit our website:

www.emeraldgrouppublishing.com/licensing/reprints.htm

Or contact us for further details: permissions@emeraldinsight.com 